\title{
MAPAS MENTAIS COMO INSTRUMENTO DE PLANEJAMENTO NO ENSINO JURÍDICO
}

\author{
Frederico de Andrade Gabrich ${ }^{1}$ \\ Ranieri Jésus de Souza ${ }^{2}$
}

\begin{abstract}
RESUMO:
Um dos maiores problemas enfrentados pelos professores é o planejamento das aulas e a preparação dos conteúdos que serão ministrados. É necessário respeitar os programas das disciplinas, mas também estabelecer prioridade entre os temas, vincular os assuntos com as fontes do Direito, conectar teoria e prática, garantir uma abordagem inter, multi e transdisciplinar. Com fundamento no método hipotético-dedutivo e com amparo no referencial teórico estabelecido por Tony Busan, o presente artigo tem como objetivo demonstrar como tudo isso pode ser realizado por meio do uso dos mapas mentais no ensino jurídico.
\end{abstract}

PALAVRAS-CHAVE: Planejamento; Mapa Mental; Ensino jurídico; Metodologia; Inovação.

\section{MENTAL MAPS AS A PLANNING INSTRUMENT IN LEGAL TEACHING}

\begin{abstract}
:
One of the biggest problems faced by teachers is the planning of the classes to prepare the contents that will be given. It is necessary to respect the syllabus of the disciplines, but also to establish priority among the themes, to link the subjects with the sources of the Law, to connect theory and practice, to guarantee an inter, multi and transdisciplinary approach. Based on the hypothetical-deductive method and supported by the theoretical framework established by Tony Busan, this article aims to demonstrate how all this can be accomplished through the use of mental maps in legal education.
\end{abstract}

KEY WORDS: Planning; Mental map; Legal education; Methodology; Innovation

\section{INTRODUÇÃO}

Um dos maiores desafios enfrentados pelos professores (iniciantes ou experientes) é o planejamento das aulas e a preparação dos conteúdos que serão ministrados, independentemente da metodologia instrutivista, construtivista ou construcionista a ser usada

\footnotetext{
1 Doutor, Mestre e Especialista em Direito Empresarial/Comercial pela UFMG. Professor Adjunto da Universidade FUMEC - BH/MG (fredericogabrich@ fumec.br).

2 Mestrando em Direito na Universidade FUMEC. Professor no MEGA Concursos. Advogado (Ranieri (ranisouza2000@yahoo.com.br).
} 
em sala de aula ou fora dela. E isso é válido tanto para as atividades de ensino e extensão, quanto também para os processos sistemáticos de avaliação e de orientação dos alunos.

É necessário respeitar os programas das disciplinas, mas também estabelecer prioridade entre os temas, vincular os assuntos com as fontes do Direito, conectar teoria e prática, garantir uma abordagem inter, multi e transdisciplinar, respeitar a realidade do mercado de trabalho e os interesses dos alunos.

Mais: é preciso elaborar e entregar para os alunos, preferencialmente antes de cada aula, um material didático-instrucional que seja significativo, vinculativo e que os auxiliem efetivamente nos seus estudos, nas suas leituras solitárias.

As linguagens e os métodos de ensino usados na sala de aula são diferentes daqueles usados na doutrina dos livros-texto e dos artigos científicos, no texto da norma, nos acórdãos da jurisprudência, nos atos administrativos e nos contratos. Todavia, cabe ao professor de Direito estabelecer e utilizar mecanismos, metodologias e métodos de ensino e de aprendizagem que permitam a interconexão dessas linguagens, com o objetivo de promover e ampliar a capacidade de compreensão e entendimento dos alunos, mesmo diante de uma realidade em constante mudança, decorrente, inclusive e sobretudo, dos avanços tecnológicos e dos meios de comunicação.

Os tempos atuais são marcados pela ampliação da capacidade de se armazenar e guardar informações e formas de conhecimento. Pessoas do mundo inteiro se interligam pela internet, o que proporciona uma grande difusão de culturas, de imagens, de vídeos e de informações. Mas não se trata apenas de uma era de informações, mas também de uma era de interação e de colaboração (quase gratuita) de conhecimento, haja vista que as pessoas não são apenas receptoras das informações, mas também produzem e divulgam conhecimento, por meio de inúmeras e múltiplas interações sociais (sobretudo digitais).

Na teoria e na prática, o discente do século XXI tem à sua disposição uma grande quantidade de informações, livros, materiais, imagens, vídeos, que aumentam significativamente a sua capacidade de aprendizado e de interação com outras pessoas que absorvem e também geram conteúdo. A internet permite a transmissão de informações e a colaboração de conhecimento em tempo real, sobre quase todo tipo de assunto, inclusive jurídico. Com o uso de dispositivos móveis, como tablets e smartphones, o aluno tem a capacidade de acompanhar as informações recebidas, inclusive fazendo consultas em tempo real na internet sobre detalhes de determinado assunto ou matéria. Há, ainda, uma grande 
variedade de cursos on-line (pagos ou gratuitos), que permitem a repetição inúmeras vezes do mesmo ensinamento, com volta ou consulta aos tópicos que causam dúvidas, bem como com a possibilidade de um aprendizado mais acelerado, em que o aluno aprende individualmente, em um ritmo mais rápido do que aquele ditado pelo professor nas aulas expositivas tradicionais.

Contudo, este grande avanço tecnológico, social, político e econômico não elimina a necessidade de o professor planejar as suas aulas e orientar os estudos e trabalhos dos seus alunos.

Na mesma proporção como são necessárias mudanças nas metodologias e métodos de ensino jurídico, são fundamentais as mudanças no planejamento das aulas de Direito, para que elas tenham realmente condições de despertar a atenção e o interesse do aluno, de modo que ele se torne elemento ativo e fundamental do processo de aprendizagem.

Com fundamento no método hipotético-dedutivo e com amparo no referencial teórico estabelecido por Tony Busan, o presente artigo tem como objetivo demonstrar como tudo isso pode ser realizado por meio do uso dos mapas mentais, sobretudo no planejamento das aulas do ensino jurídico, tanto nos cursos de graduação, quanto nos de pós-graduação, como também nos cursos preparatórios para exames de suficiência profissional ou para concursos públicos.

\section{A IMPORTÂNCIA DO PLANEJAMENTO NO ENSINO}

$\mathrm{O}$ sucesso em qualquer atividade profissional de natureza intelectual geralmente depende do encadeamento e da organização estruturada de cinco elementos fundamentais: a ideia, o planejamento, o conhecimento, a experiência e a execução. Quase tudo começa de forma subjetiva com uma ideia, com um "sonho", mas sem o planejamento, o conhecimento, a experiência e a execução, a ideia se esvai, sem nenhuma concretude, sem nenhuma alteração no estado de fato ou de direito da vida. Assim também ocorre com o trabalho do professor universitário, independentemente do curso que leciona.

Nesse sentido, segundo Antônio Carlos Gil:

O início das atividades do professor universitário não se dá no primeiro dia de aula. Suas tarefas começam com o planejamento, que se inicia algumas semanas ou alguns meses antes, dependendo da experiência do professor com a disciplina que pretende lecionar. Por mais erudito e experiente que seja, ele não pode dispensar essa etapa, pois graças a ela é que seu trabalho assume racionalidade e permite que seja avaliado. 
O planejamento requer do professor algumas habilidades distintas daquelas que estão diretamente relacionadas à prática docente. Como foi lembrado no Capítulo 3, o professor universitário desempenha diferente papéis, e um deles é o de planejador, o que não o torna diferente de outros profissionais, com exceção, provavelmente, daqueles que se ocupam de atividades puramente braçais ou mecânicas. Isto porque o estágio atual de desenvolvimento da Humanidade requer dos seres humanos, dentre outras, a capacidade de previsão. É preciso "saber para prever e prever para poder", como dizia Augusto Comte, já no século XIX.

A maioria dos professores universitários reconhece a importância do planejamento do ensino. Mas nem todos planejam seus cursos de maneira criativa. Muitos simplesmente seguem os capítulos de um livro-texto, sem considerar o que é realmente necessário que os alunos aprendam. Também é grande o número de professores que utilizam sem muita reflexão os mesmos métodos de ensino e os mesmos procedimentos de avaliação (GIL, 2012, p. 94).

Entretanto, Lowman observa, que:

Muitos professores universitários são ambivalentes em relação ao planejamento. Embora possam endossar, em teoria, o valor do planejamento educacional, poucos plaejam seus cursos criativa e independentemente, saindo do currículo tradicional para selecionar os conceitos que acreditam ser mais fundamentais ou para adotar métodos inovadores de ensinálos. De modo semelhante aos estudantes submissos, que fazem apenas aquilo que lhes é pedido, demasiados professores adotam receitas de planos de aula ou seguem os títulos dos capítulos de um livro-texto, sem considerar o que os estudantes devem realmente aprender em seus cursos. Professores demais também escolhem, sem muita reflexão, os mesmos métodos de ensino, continuando a confiar principalmente em algumas variações da preleção/discussão. A maior parte dos professores excelentes, por outro lado, planeja sua alua muito seriamente, totalmente consciente de que existem formas alternativas de organizar as aulas para promover o aprendizado e a motivação em nível elevado, o que vai além da mera apresentação da matéria (LOWMAN, 2004, p. 185-186).

Não obstante, conforme Gabrich:

Planejar é, em síntese, construir cenários possíveis, com objetivo de antever ou antecipar o futuro, para a concretização dos objetivos estabelecidos antes. Nesse sentido, o planejamento implica a elaboração de um conjunto de ações voltadas para implementação dos objetivos pré-determinados (GABRICH, 2010, p. 14).

De fato, o planejamento do ensino ocorre em diversos níveis. Nesse sentido, em primeiro plano, há o Planejamento Educacional que se desenvolve em nível mais amplo para definição dos objetivos finalísticos da atividade educacional e que é realizado pelas autoridades educacionais (Ministério da Educação, Conselho Nacional de Educação, Secretarias estaduais e municipais de educação). Em segundo lugar, há o Planejamento Institucional, realizado pelas próprias instituições de ensino, por meio de suas propostas pedagógicas, missão e objetivos gerais, expostos em seus Planos de Desenvolvimento Institucionais (PDI's), em cumprimento do disposto na Lei de Diretrizes e Bases da Educação (Lei n. 9.394/94). Em terceiro lugar, o planejamento da atividade educacional acontece, no âmbito das instituições de ensino superior, por meio do Planejamento Curricular de cada curso oferecido, com a definição das ações que serão desenvolvidas para favorecer ao máximo o ensino e a aprendizagem, considerando-se os limites delimitados pelas diretrizes 
curriculares fixadas pelo Conselho Nacional de Educação. Em quarto lugar, há o Planejamento do Ensino, que ocorre em nível mais concreto por meio do trabalho dos professores, que estabelecem os temas, o conteúdo, as referências, o direcionamento das atividades que serão realizadas dentro e fora das salas de aula pelos alunos, a partir das suas necessidades. Para o Planejamento do Ensino, geralmente os professores elaboram o Plano de Ensino, o Plano de Unidade e o Plano de Aula da disciplina (GIL, 2012).

Apesar de os mapas mentais poderem ser utilizados como ferramenta do planejamento educacional em todos os níveis, facilitando sobremaneira a sua divulgação e compreensão pelas pessoas a quem se dirigem, esta pesquisa tem como objetivo específico demonstrar a sua utilidade dos mapas mentais, sobretudo, no âmbito do Planejamento do Ensino realizado concretamente pelos professores, especialmente por intermédio dos Planos de Aula.

Realmente, o Plano de Aula é constituído pela definição do conteúdo, preferencialmente disciplinar, interdisciplinar, multidisciplinar e transdisciplinar que será objeto das aulas desenvolvidas com e/ou pelos alunos, seja por meio de metodologias instrutivistas (aulas expositivas e seminários), construtivistas (estabelecem conexão do conteúdo teórico com a prática e com a vida do aluno) ou construcionistas (ativas, em que o aluno aprende fazendo e assume o papel central do processo de ensino-aprendizagem) (GABRICH, 2013). Além disso, por meio do Plano de Aula, concretamente, o professor faz escolhas (de objetivos, de temas, referências, histórias, conexões), planeja atividades, elabora avaliações e também o próprio material instrucional que idealisticamente deve ser antes disponibilizado para os discentes.

Nesse sentido, como ressalta Lemov:

O plano de aula vem depois do processo de planejamento da unidade e consiste em:

1. Refinar e aperfeiçoar o objetivo com base no resultado da aula anterior - se a classe atingiu o objetivo de ontem.

2. Planejar uma curta avaliação diária, que vai determinar se o objetivo foi atingido.

3. Planejar a atividade, ou melhor, uma série de atividades que levem ao domínio do objetivo (LEMOV, 2011, p. 77).

Ocorre que este trabalho docente, nos dias atuais, é realizado em meio a um ambiente absolutamente diferente daquele observado, por exemplo, nos anos 1980 e início dos anos 1990, sobretudo em virtude da revolução dos meios de informação e comunicação, determinada, principalmente, pela onipresença da internet na vida contemporânea.

Nesse sentido, de acordo com Gabrich:

A realidade do Século XXI é completamente diferente daquela vigente nos séculos anteriores, e as mudanças ocorridas nos últimos tempos têm efeito direto nas novas gerações de estudantes 
de Direito, que têm hoje novos interesses. De acordo com a lógica do mercado capitalista, a mudança do perfil da clientela exige a mudança do perfil do produto e/ou do serviço que lhe é oferecido, sob pena do desinteresse e do excesso de oferta daquilo que ninguém quer ou precisa, com a queda inexorável do preço. Nos cursos de Direito atuais, com raras exceções, a mudança dos interesses da clientela não determinou a mudança do perfil do produto/serviço que lhe é oferecido. Essa situação criou um círculo vicioso de desinteresse, de excesso de oferta, de baixa demanda e de preços cada vez mais baixos (GABRICH, 2013, p.1).

O mesmo autor acrescenta, ainda, que:

O ensino do Direito precisa evoluir na mesma medida das evoluções ocorridas desde antes do início formal do Século XXI e que perduram até os dias atuais. A realidade social, econômica, política e cultural da maioria dos países e o interesse dos alunos dos cursos de graduação - inclusive em Direito - mudaram completa e radicalmente nos últimos 25 anos. Todavia, os processos de formação do conhecimento e, principalmente, as metodologias de ensino, de avaliação e até de pesquisa científica, especialmente no âmbito jurídico, não evoluíram na mesma proporção.

Essa situação estabeleceu um significativo descompasso entre os interesses acadêmicos e profissionais dos alunos dos cursos de graduação, as necessidades do mercado, e as formas de ensino, de pesquisa e de avaliação perpetrados pelas Universidades (GABRICH, 2013, p.2).

Assim, na mesma proporção como é preciso ocorrer uma evolução significativa nas metodologias e nos métodos de ensino jurídico, de modo a despertar o interesse, a motivação e a efetiva participação do discente no processo de aprendizagem (especialmente nos cursos jurídicos), é preciso estabelecer uma evolução do trabalho dos professores, que começa com o Plano de Ensino, eventualmente passa pelo Plano de Unidade, mas concretamente deságua no Plano de Aula da disciplina, ou seja, naquilo que concretamente será feito com e pelos alunos, na sala de aula e fora dela, a partir do direcionamento, da liderança e do trabalho do professor.

O planejamento das aulas por meio de Mapas Mentais é uma das alternativas viáveis e factíveis para responder a todas essas demandas, especialmente nos cursos jurídicos, quer nos níveis de graduação e de pós-graduação, quer nas atividades de extensão e de pesquisa, quer nos cursos preparatórios direcionados para exames de suficiência profissional ou para aprovação em concursos públicos.

\section{O MAPA MENTAL}

O Mapa Mental é um método de ensino e aprendizagem, que normalmente pode ter conexão com todas as metodologias de ensino (instrutivistas, construtivistas e construcionistas), dependendo de como ele é utilizado pelo professor.

De fato, o Mapa Mental é um método de armazenar, organizar e priorizar informações, usando Palavras-Chave e Imagens-Chave, que desencadeiam lembranças específicas e 
estimulam novas reflexões e ideias, tendo sido sua teorização desenvolvida, sobretudo, pelo trabalho do inglês Tony Buzan.

Buzan assim descreve o conceito de Mapa Mental:

O Mapa Mental (Mind Map) é uma ferramenta dinâmica e estimulante que contribui para que o pensamento e o planejamento se tornem atividades mais inteligentes e rápidas. A criação de um Mapa Mental é um método inovador que permite explorar os infinitos recursos do cérebro, tomar decisões apropriadas e entender nossos sentimentos.

Os Mapas Mentais são um método de armazenar, organizar e priorizar informações, usando Palavras-Chave e Imagens-Chave, que desencadeiam lembranças específicas e estimulam novas reflexões e ideias. Cada ativador da memória em um Mapa Mental é uma chave que dá acesso a fatos, ideias e informações, além de liberar o verdadeiro potencial da mente, de modo que possamos nos tornar o que quisermos ser (BUZAN, 2009, p. 3).

Os Mapas Mentais podem ser usados para uma infinidade de atividades, como leitura, revisão de conteúdos, desenvolvimento de ideias, de projetos, de tempo, planejamento de atividades educacionais, de lazer e apresentações. Pode ser usado na escola, no trabalho, em casa e na vida social.

Para entender melhor o conceito e a utilização de um Mapa Mental, Tony Buzan destaca que é importante entender como funciona o cérebro humano. Ele explica que este órgão é um processador extraordinário, capaz de realizar infinitas reflexões e que tem cinco funções principais: recepção, armazenamento, análise, controle e expressão. O Mapa Mental é projetado para que o cérebro utilize estas habilidades, armazenando ou recuperando informações facilmente.

De fato, é preciso saber mais sobre como o cérebro recebe, processa, analisa, retém (armazena) e recupera informações, pois isso é absolutamente fundamental tanto para a criação, para o compartilhamento e para o desenvolvimento das ideias, quanto para o desenvolvimento de métodos de ensino e aprendizagem, entre os quais podem ser destacados os Mapas Mentais.

Tony Buzan percebeu que o ser humano, desde o momento em que aprende a ler e a escrever, comunica-se, expressa ideias e transmite seus conhecimentos por meio de palavras, faladas ou escritas. Porém o cérebro humano, como observado por Buzan, é um órgão superpoderoso, que pode absorver, interpretar e recuperar informações por meios de recursos que vão bem além de palavras faladas ou escritas.

Nas palavras de Tony Buzan:

Como falamos e escrevemos usando frases, presumimos que ideias e informações devem ser armazenadas de forma linear ou como uma lista. Isso é um procedimento que nos limita, como você verá. 
Na fala, só podemos dizer uma palavra por vez. Do mesmo modo, na comunicação escrita as palavras são apresentadas em linhas e sentenças, com começo, meio e fim. A ênfase na linearidade também está presente nas instituições de ensino e no trabalho, áreas em que a maioria das pessoas é estimulada a tomar notas em forma de frases ou lista.

A limitação desta abordagem é que podemos demorar um bocado de tempo para chegar à essência do assunto em questão. E, durante este processo, dizemos, ouvimos ou lemos muitas coisas que não são importantes a longo prazo.

As pesquisas mostram que o cérebro é um órgão multidimensional, capaz de absorver, interpretar e recuperar informações por meio de recursos que são muito mais sensitivos, criativos, multifacetados e instantâneos do que as palavras escritas e faladas. A mente é capaz de entender uma informação não linear, pois é projetada para essa função. E ela faz isto o tempo todo, seja quando vemos fotografias e figuras, seja quando interpretamos outras imagens que estão ao nosso redor.

Quando o cérebro ouve uma série de frases, ele não absorve a informação palavra a palavra, linha a linha - ele a considera como um todo. Ele a classifica, interpreta e assimila de diversas maneiras. Ouvimos as palavras e as situamos no contex to do conhecimento que já possuímos.

Não temos necessidade de escutar todo um conjunto de frases antes de elaborarmos uma resposta (BUZAN, 2009, p. 8-9).

Tony Buzan fala sobre o Pensamento Radiante. Quando a pessoa pensa em uma determinada palavra, como na palavra "banana", o cérebro imediatamente apresenta uma imagem, a pessoa pensa no sabor, a pessoa faz associações geralmente não lineares. Nesse sentido, Buzan explica:

O cérebro tem a capacidade de criar uma infinidade de ideias, imagens e conceitos. Um Mapa Mental é projetado para trabalhar do mesmo modo que este órgão e é uma representação, no papel, do Pensamento Radiante em ação. Quanto mais você conseguir armazenar informações de uma forma que se assemelhe à maneira como o cérebro funciona naturalmente, mais facilidade ele terá para se recordar de fatos importantes e memórias pessoais (BUZAN, 2009, p. 11).

Buzan ensina que o cérebro humano pensa em várias direções ao mesmo tempo, não agindo de forma linear e monótona, mas partindo de ativadores centrais presentes, que Buzan chama de Palavras-Chave ${ }^{3}$ ou Imagens-Chave ${ }^{4}$.

Para exemplificar, ele ilustra a situação de determinada pessoa que liga para uma atendente de uma companhia aérea para saber se ainda há lugar em determinado vôo. Antes de mais detalhes sobre o vôo, a atendente informa que os aviões da empresa estão decolando

\footnotetext{
${ }^{3}$ A Palavra-chave é um termo especial que é escolhido ou criado para ser uma referência única a algo importante de que desejamos nos lembrar. As palavras estimulam o lado esquerdo do cérebro e são um recurso vital para mantermos o domínio da memória. Porém, são mais eficazes quando transformadas em Imagens-Chave, pois somente desta forma conseguem ativar os dois lados do cérebro (BUZAN, 2009, p.4).

${ }^{4}$ As Imagens-chave constituem a base da memória. Eu as chamo de Imagens-Chave da memória verbal nos meus livros porque elas são combinações de palavras e imagens cuidadosamente construídas para trazerem à mente lembranças armazenadas no fundo da memória. Uma Imagem-chave é muito mais do que uma simples figura. É uma imagem associada a uma Palavra-chave para estimular a imaginação e recriar associações familiares. Quando eficaz, ativa os dois lados do cérebro e usa todos os sentidos. As Imagens-chave são o elemento central das minhas técnicas de memorização e de criação de Mapas Mentais (BUZAN, 2009, p.4).
} 
com atraso. Ao ouvir a palavra "atraso", o cérebro humano começa imediatamente a fazer inúmeras associações: a volta para casa, passar a noite em sua própria cama, o som do altofalante no aeroporto. Instantaneamente, o cérebro começa a pensar alternativas, como voltar de ônibus, ir para o aeroporto, dormir em um hotel. Todas essas reações foram provocadas pela palavra "atraso". Neste ponto, a palavra "atraso" funcionou como uma Palavra-Chave, que desencadeia uma imediata reação multifacetada.

A mesma situação ocorre quando o cérebro analisa uma imagem. Quando o olho humano visualiza a imagem de um carro, o cérebro começa imediatamente a fazer associações: quanto custa aquele carro, se a pessoa gosta daquele carro, qual a cor mais bonita daquele carro. Faz a pessoa pensar em determinada viagem, pensar na família, pensar em possuir aquele veículo.

Nos Mapas Mentais, a ideia central é representada por uma imagem, que é denominada de Imagem-Chave.

Buzan explica:

O ditado que diz que "uma imagem vale mais do que mil palavras" é verdadeiro. Em um experimento, cientistas mostraram a um grupo de pessoas 600 imagens, uma por segundo. Depois da apresentação, foi feito um teste para analisar a capacidade que os participantes tinham de lembrar com exatidão do que haviam visto. Noventa e oito por cento deles se recordaram com precisão das imagens exibidas. Para o cérebro humano, é muito mais fácil resgatar memórias de imagens do que de palavras. É por isto que, em um Mapa Mental, a ideia central é representada por uma imagem. Usar imagens em diversos lugares do seu Mapa Mental também é importante (BUZAN, 2009, p.15).

Buzan trata sobre as Ideias de Ordenação Básicas (IOBs). Elas são assuntos-chave essenciais em torno dos quais todos os outros assuntos podem ser organizados. As IOBs seriam, em uma equivalência, como os títulos dos capítulos de um determinado livro. Em um Mapa Mental pode ser estabelecida mais de uma Ideia de Ordenação Básica.

O Mapa Mental, tal como idealizado por Buzan não deve ser confundido com esquemas, gráficos, organogramas ou fluxogramas. Cada uma destas ferramentas apresenta suas próprias características, geralmente sem imagens, sem cores, sem destaques, contendo muitas vezes frases e palavras repetitivas. O Mapa Mental é elaborado com uso de determinadas regras, que Buzan divide em regras Técnicas e regras de Desenho.

As regras técnicas se dividem em quatro tópicos: destaques, associações, clareza e estilo pessoal. Já as regras de desenho se dividem em dois tópicos: hierarquia e ordem numérica. 
Assim, consideradas as regras técnicas e de desenho, podemos destacar as seguintes recomendações de Tony Buzan para a elaboração de um Mapa Mental:

\section{Regras técnicas de destaque:}

- Destacar uma imagem central para chamar a atenção dos olhos e do cérebro; usar imagens por todo o mapa, para estabelecer um foco e estimular o lado direito e esquerdo do cérebro.

- Destacar três ou mais cores por imagem central, pois estas estimulam a memória e a criatividade.

- Colocar perspectivas nas imagens e ao redor das palavras, pois isto contribui para que certos elementos se destaquem.

- Usar variações nos tamanhos de letras, linhas e imagens, pois isto estabelece uma hierarquia entre as informações destacadas.

\section{Regras técnicas de associações:}

- Usar setas para estabelecer conexões entre as ramificações, pois as setas guiam o olhar de um modo que automaticamente une as coisas.

- Usar cores, com o objetivo de intensificar a memória e a criatividade.

- Usar códigos como asteriscos, cruzes, triângulos e sublinhados, pois estes poupam tempo, haja vista que permitem a realização de conexões instantâneas entre diferentes partes do Mapa Mental.

\section{Regras técnicas de clareza:}

- Usar apenas uma palavra-chave por linha, pois uma palavra remete a milhares de significados e associações.

- Escrever as palavras em letra de forma, isto facilita o trabalho da mente em "fotografar" e armazenar a informação.

- Escrever as palavras-chave vinculadas às linhas, pois isto facilita o cérebro a estabelecer ligações com o restante do Mapa. 
- Cuidar para que as palavras tenham o mesmo cumprimento da linha, que entre outras vantagens, traz economia de espaço que pode ser utilizado em outras informações no Mapa Mental.

- Fazer linhas centrais mais grossas do que as outras, pois isto indica ao cérebro que elas são mais importantes.

- Criar formas e limites em torno das ramificações.

- Criar o Mapa Mental, mantendo o papel posicionado horizontalmente, no formato "paisagem".

\section{Regras técnicas de estilo pessoal:}

- Na elaboração do Mapa Mental, cada um pode desenvolver o seu estilo pessoal, usando cores preferidas, estilo, despertando a imaginação.

\section{Regras de desenho - hierarquia:}

- Fazer distinção entre níveis de hierarquia e de importância ajuda o cérebro a se lembrar de fatos essenciais.

\section{Regras de desenho - ordem numérica:}

- Ordenar os pensamentos em ordem cronológica ou de importância. Para isto basta numerar as ramificações na ordem desejada.

Todas essas regras ajudam na elaboração do Mapa Mental, fazendo com que ele se diferencie de outras ferramentas como esquemas, gráficos, organogramas ou fluxogramas e se identifique com as características que lhe são próprias.

Nesse sentido, destaca-se o exemplo abaixo: 


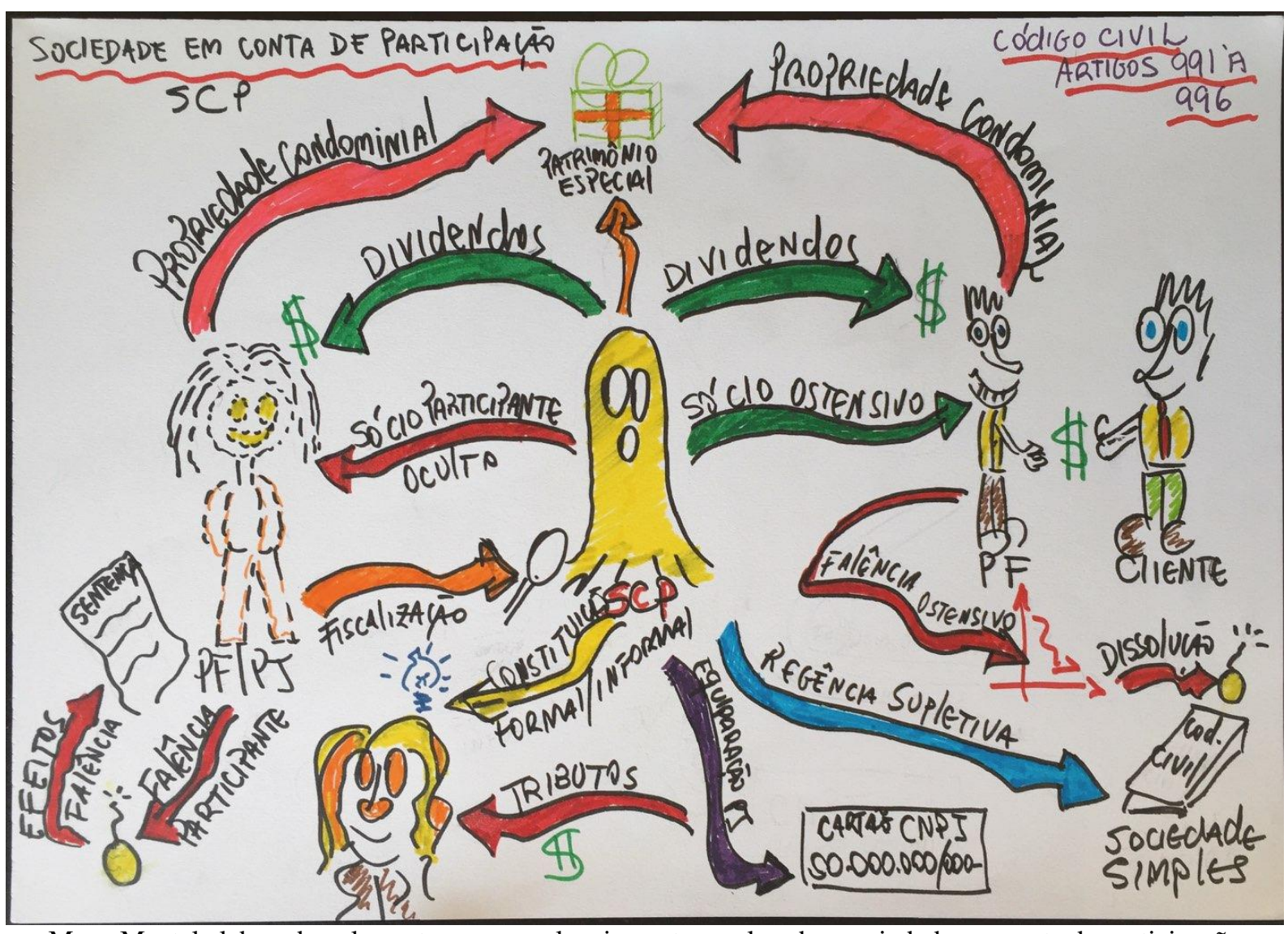

Mapa Mental elaborado pelos autores, para planejamento e aula sobre sociedade em conta de participação

Como se pode observar acima, o Mapa Mental apresenta inúmeros recursos em relação ao método tradicional de anotações lineares e pode ser usado com eficiência na elaboração de Planos de Aula pelos professores, inclusive nos cursos jurídicos.

De qualquer maneira, Buzan (2009) destaca que as vantagens do Mapa Mental em relação a outras formas de planejamento e de apresentação de ideias e conteúdos ocorrem, porque:

a) A ideia principal é definida com maior nitidez;

b) A importância relativa de cada ideia é especificada com clareza;

c) As ideias mais importantes se destacam e são reconhecidas de imediato no centro do Mapa Mental;

d) As ligações entre os conceitos-chaves são identificadas com facilidade e isto estimula a associação de ideias;

e) A revisão das informações é eficiente e rápida;

f) A estrutura de um Mapa Mental permite que a qualquer momento, com facilidade, sejam acrescentados conceitos adicionais; 
g) Os Mapas Mentais são criações únicas, e por isso, fazem com que as lembranças sejam mais exatas

É importante destacar que tanto a pessoa que assiste à exposição, como aquela que está apresentando, tem dois grandes benefícios ao visualizar o Mapa Mental. Primeiro, tem uma visão global de todo o assunto que será abordado. Segundo, além de visualizar os fatos, consegue identificar a ligação entre eles. Essas duas situações geralmente não se encontram presentes na exposição de um texto de forma linear.

\section{MAPA MENTAL E O ENSINO JURÍDICO}

Tony Buzan (2009) destaca que "os Mapas Mentais podem ser usados em todas as ocasiões”. O autor ressalta situações como uso do Mapa Mental para organização de uma agenda, para um planejamento anual, mensal e diário, para ajudar na organização de atividades em casa, no trabalho e na escola ou mesmo para resolver problemas em equipe e para compartilhar resultados.

Nesse sentido, Letícia da Silva Almeida e Sérgio Henriques Zandona Freitas ressaltam:

Não há dúvida de que os mapas mentais podem (e devem) ser utilizados na sala de aula pelo docente, no desenvolvimento do conteúdo, para facilitar a melhor compreensão e assim, favorecer a ligação do raciocínio lógico e emocional do discente, despertando maior interesse da comunidade acadêmica (ALMEIDA; CASTRO; FREITAS, 2017). O docente também deve orientar e estimular o aluno a utilizar os Mapas Mentais em seus estudos individuais, ao invés de recorrer aos resumos comuns.

Os Mapas Mentais têm sido comumente utilizados por pessoas que almejam resultado positivo em concursos públicos, já que essa ferramenta possibilita uma visão geral do conteúdo estudado, necessitando, assim, quantidade de tempo consideravelmente menor em relação a utilização de resumos, além de outros benefícios já mencionados nesta pesquisa. Além disso, os mapas mentais também podem ser utilizados em escritórios de advocacia, por profissionais do Direito. Os advogados podem fazer mapas mentais para esboçar a situação do seu cliente, além de não perder o domínio dos acontecimentos, possibilitando visão global do problema ao encontrar a melhor estratégia para a solução mais viável, econômica e menos desgastante na defesa do seu cliente.

Mapas Mentais podem também ser utilizados em reuniões, palestras, organização de apresentações ou aulas. Tony Buzan diz que a vantagem "é que o Mapa Mental dá ao professor ou ao palestrante uma visão geral de todo o assunto a ser abordado" (BUZAN, 2009, p. 77). (ALMEIDA; FREITAS, 2017, p.13).

Assim, é evidente o número exponencial de situações que permitem a utilização do Mapa Mental em atividades pessoais, de estudo e profissionais.

Como foi demonstrado acima, o Mapa Mental apresenta inúmeros recursos e vantagens em relação ao método tradicional de anotações lineares e pode ser usado com 
eficiência na elaboração de Planos de Aula nos cursos jurídicos, pois, além de orientar o trabalho do professor em sala de aula, serve totalmente de material instrucional para os alunos, que podem utilizá-lo para orientação dos estudos no livro-texto, memorização de conceitos e das conexões necessárias para uma análise crítica disciplinar, interdisciplinar, pluridisciplinar e transdisciplinar do tema abordado.

Apesar de toda evolução tecnológica e científica e das importantes transformações econômicas, políticas, históricas e sociais ocorridas, o sistema de ensino nos cursos jurídicos permanece, em regra, em descompasso com todos esses acontecimentos, não tendo evoluído na mesma proporção dos desejos e das necessidades dos alunos. O resultado se constata visivelmente, com o uso preferencial das metodologias instrutivistas e dos métodos tradicionais de ensino e de avaliação que se perpetuam, sem mudanças realmente significativas. Aulas baseadas quase que exclusivamente no conhecimento e na experiência do professor, ou do livro-texto, sendo transmitidas de forma essencialmente expositiva, por meio de um monólogo conduzido pelo professor, que muitas vezes ainda exige ou estimula que o discente faça inúmeras anotações, muitas das quais desnecessárias no seu dia a dia, na sua experiência profissional e ainda, na sua colocação no mercado de trabalho. Isso tudo muitas vezes leva o aluno a uma total desmotivação e desinteresse pela matéria e às vezes até pelo curso de Direito.

É notório que o aluno de hoje não se limita a buscar informações apenas no conhecimento do professor. Livros digitais, acesso em tempo real a quase tudo pela internet $\mathrm{e}$ aulas gravadas disponibilizadas pelas redes sociais são exemplos de ferramentas à disposição do discente, que, nos tempos atuais, até mesmo se utiliza desses artifícios para questionar o conhecimento e os métodos tradicionais de ensino usados pelo professor.

Todo esse contexto ressalta a necessidade de uma mudança impactante, que apresente aulas atraentes, participativas, capazes de permitir ação-reflexão-ação do aluno, tanto em relação ao conteúdo da disciplina, como em relação à teoria e à prática de outras disciplinas do mesmo curso e de outros.

E o uso de novos métodos de planejamento e de ensino, entre as quais se insere o Mapa Mental, pode significar um caminho para a mudança almejada, para despertar novamente o interesse do aluno e para permitir a formação de profissionais realmente capacitados para atender às demandas mutantes do mercado.

Nesse sentido, Gabrich e Benedito destacam: 
O ensino e a prática jurídica brasileira, indiscutivelmente, passam por uma crise que pode ser analisada a partir de diversos aspectos ideológicos, sociais, culturais, econômicos, políticos e metodológicos, sendo que a esta pesquisa, por conta de um corte epistemológico, somente interessam os aspectos metodológicos.

Antes de qualquer abordagem específica, é importante observar que a forma de pensar adotada pela maioria dos professores e demais profissionais do Direito, tem uma influência significativa não apenas na mencionada crise do ensino jurídico, mas também na própria crise das profissões jurídicas, comprovada pelo excesso de processos judiciais, pela demora e muitas vezes inconsistência da prestação jurisdicional, que corroboram o deficiente funcionamento do Poder Judiciário em muitos casos da prática.

Nesse sentido, o ensino e a prática jurídica brasileiros são desenvolvidas, quase sempre, a partir de uma mesma forma de pensar, de um modelo mental dominante e já destacado acima. De acordo com esse modelo mental que ainda prevalece como forma de pensar da maioria dos profissionais do Direito (inclusive professores e alunos dos cursos jurídicos), todas as ideias devem ser desenvolvidas a partir da análise de um fato único e isolado dos demais fatos e pessoas.

Além disso, de acordo com essa forma de pensar ainda dominante, o Direito é sempre considerada uma ciência normativa voltada para a determinação daquilo que é certo ou errado em um determinado lugar e/ou momento. Nesse modelo, o Direito é compreendido também como a ciência da (suposta) solução de conflitos (sempre pressupostos por quem ensina, interpreta e aplica o Direito), quase sempre por meio da intervenção estatal e de um processo judicial. Além disso, de acordo com esse modelo dominante de pensamento, a fonte primária, mais importante e (quase) única do Direito é a lei formal, já que, de acordo com a máxima positivista expressa no texto constitucional, "ninguém é obrigado a fazer ou deixar de fazer alguma coisa, senão em virtude de lei” (art. 5o, II, da Constituição da República) (GABRICH; BENEDITO, 2016, p. 10-11).

Os mesmos autores acrescentam, ainda, que:

Assim, como, infelizmente, o modelo mental dominante no ensino e na prática jurídica valoriza quase que exclusivamente a solução de conflitos por meio da lei e do processo judicial, são raros os casos em que o método indutivo, o pensamento sistêmico (gestáltico) e as metodologias que valorizem o pensamento divergente, radiante e criativo dos alunos e dos profissionais do Direito são utilizadas ou mesmo desenvolvidas no âmbito teórico e/ou prático. E isso acaba promovendo, cada vez mais, em um círculo vicioso, o desinteresse e o despreparo dos alunos para uma atuação profissional renovada, baseada em um modelo mental diferente do tradicional e ainda dominante, contemporâneo (e até, em certos momentos, vanguardista), conectado com as necessidades e com os desafios do século atual (GABRICH; BENEDITO, 2016, p. 12).

O uso dos Mapas Metais no ensino, em contraposição ao método tradicional de elaboração de listas e anotações monocromáticas é comentado por Tony Buzan nos seguintes termos:

Um dos resultados mais gratificantes de minha carreira tem sido o modo positivo como educadores e crianças em todo o mundo começaram a adotar Mapas Mentais, fazendo do ensino e do aprendizado um processo mais estimulante, prazeroso e eficiente.

Os Mapas Mentais são usados em cursos de treinamento de professores, na preparação de aulas, na explicação simplificada de conceitos complexos, na revisão de anotações, na síntese de livros e nas lições de casa. É possível, ainda, utilizar uma série de programas de computador altamente eficientes que criam e atualizam Mapas Mentais com rapidez e facilidade.

As tradicionais "normas" da educação dizem que a elaboração de listas e anotações monocromáticas é boa, enquanto desenhos, rabiscos e recursos imaginativos são naturalmente errados. Como você já deve ter percebido, minhas crenças e descobertas mostram que o oposto 
é verdadeiro; a anotação convencional limita o pensamento, enquanto a fantasia e o desenho intensificam o Pensamento Radiante (BUZAN, 2009, p. 38).

Resta evidenciado, então, que os Mapas Mentais podem ter grande impacto no ensino jurídico, inclusive e principalmente na fase de planejamento das aulas. O docente, ao utilizar este método, estrutura de forma mais completa a aula, mas também desperta instantaneamente o interesse do discente, que se motiva com a inovação e acaba percebendo o ganho de qualidade nos estudos, promovido pela conexão entre conteúdo, imagens e palavras-chave, permitida pelo uso do Mapa Mental. Mais: o Mapa Mental permite maior retenção de conteúdo pelo discente, de forma rápida e eficiente, sem que este tenha de fazer anotações.

O Mapa Mental pode também ser utilizado no ensino jurídico, não apenas no planejamento das aulas, mas em inúmeras outras oportunidades, como em palestras e seminários, na leitura de livros e artigos, na elaboração de estratégias jurídicas necessárias à estruturação dos objetivos das pessoas e/ou à promoção da solução extrajudicial e/ou judicial dos conflitos.

O docente tem ainda a possibilidade de incentivar os seus alunos a construírem os seus próprios Mapas Mentais que podem, inclusive, serem utilizados como instrumento bastante eficientes e diferenciados de avaliação. Nesse caso, ao invés de responder a uma questão dissertativa ou objetiva, o aluno pode elaborar o seu próprio Mapa Mental acerca do tema proposto pelo professor na prova, inclusive com a demonstração das conexões inter, multi e transdisciplinares que o assunto promove ou permite.

\section{CONCLUSÃO}

Como restou demonstrado na pesquisa, o sucesso nas atividades profissionais de natureza intelectual geralmente depende da ideação, do planejamento, do conhecimento, da experiência e da execução. E isso é absolutamente evidente em relação à atividade profissional dos professores, em todos os níveis.

No caso específico da atividade docente universitária, um dos maiores desafios enfrentados pelos professores no dia a dia é o planejamento das atividades de ensino e de aprendizagem, que precisam garantir a interação com os alunos, bem como ação-reflexãoação, análise crítica inter, multi e transdisciplinar, por meio de atividades de ensino, de 
pesquisa e de extensão, que garantam também a conexão entre a teoria e a prática, além do ativismo discente.

Tudo isso não é fácil de ser estabelecido no ensino superior de maneira geral e nos cursos jurídicos de maneira específica, pois os professores estão vinculados a uma tradição metodológica instrutivista, e os alunos atuais estão inseridos em um contexto em que as informações e o conhecimento são disponibilizados de forma imediatista, multimídia, massiva, quase gratuitas e de forma exponencial pela internet.

Os professores dos cursos jurídicos precisam, além de superar o modelo metodológico tradicional, planejar as suas atividades de ensino de forma significativa, vinculativa, emocional e ainda elaborar materiais instrucionais que facilitem o entendimento dos conceitos e das finalidades dos institutos, a análise crítica e contextualizada com a vida do aluno, a interação entre a teoria e a prática, a conexão inter, multi e transdisciplinar.

Muitos desses objetivos podem ser alcançados por meio do uso dos Mapas Mentais, tanto na elaboração dos Planos de Aula, quanto dos materiais instrucionais, como no desenvolvimento das atividades na sala de aula (independentemente da metodologia instrutivista, construtivista ou construcionista utilizada), como, ainda, na implementação de avaliações inovadoras.

\section{REFERÊNCIAS}

BUZAN, Tony. Mapas Mentais: métodos criativos para estimular o raciocínio e usar ao máximo o potencial do seu cérebro. Rio de Janeiro: Sextante, 2009.

FREITAS, Sérgio Henriques Zandona; ALMEIDA, Letícia da Silva. Mapa mental e o ensino jurídico: uma forma visual de efetivar o conhecimento científico no curso de direito. Revista de sociologia, antropologia e cultura jurídica, v. 3, p. 1-17, 2017.

GABRICH, Frederico de Andrade; BENEDITO, Luiza Machado Farhat. Mapa Mental no Ensino Jurídico. Anais do V Congresso Internacional do CONPEDI - Conselho Nacional de Pesquisa e Pós-Graduação em Direito. 2016. 
GABRICH, Frederico de Andrade. Análise Estratégica do Direito. Belo Horizonte:

Universidade Fumec, 2010.

GABRICH, Frederico de Andrade. Transdisciplinaridade no ensino jurídico. In: XXII Encontro Nacional CONPEDI, 2013, Curitiba. Direito, educação, ensino e metodologia jurídicos. Florianópolis: FUNJAB, 2013. v. 1. p. 372-387.

GIL, Antônio Carlos. Didática do ensino superior. São Paulo: Atlas, 2012.

LEMOV, Doug. Aula nota 10: 49 técnicas para ser um professor campeão de audiência. Tradução de Leda Beck. São Paulo: Fundação Lemann, 2011.

LOWMAN, Joseph. Dominando as técnicas de ensino. Tradução Harue Ohara Avritscher. São Paulo: Atlas, 2004. 